\title{
DIÁRIO DA QUARENTENA DE UMA PROFESSORA DA PRIMEIRA INFÂNCIA: APROXIMAÇÕES COM BOAVENTURA, AGAMBEN E KRENAK
}

\author{
Isabela Pereira Lopes ${ }^{\mathrm{i}}$
}

Resumo: O presente relato de experiência parte da constatação do quanto é difícil ter concentração e inspiração para ler, escrever e estudar na quarentena, assim a autora se aproxima de intelectuais de nossa contemporaneidade que estão aceitando esse desafio, de pensar criticamente o tempo presente, que é inédito e raro para nossa geração. São realizadas aproximações com Boaventura de Sousa Santos, Ailton Krenak e Giorgio Agamben, que escreveram livros na/da pandemia. Inspirada por esses pensadores, a autora levanta suas próprias impressões sobre a pandemia e suas repercussões numa instituição de Educação Infantil, no qual a mesma foi empossada durante o período de distanciamento social.

Palavras-chave: Pandemia; Educação infantil; Diário da quarentena.

\section{QUARANTINE DIARY OF A FIRST CHILDHOOD TEACHER: APPROACHES WITH BOAVENTURA, AGAMBEN AND KRENAK}

\begin{abstract}
The present experience report partly ascertaining how difficult it is to have concentration and inspiration to read, write and study in quarantine, just as an author approaches intellectuals of our contemporary who are accepting this challenge, to think critically or in present time, which is credited and rare for our generation. Approaches are made with Boaventura de Sousa Santos, Ailton Krenak and Giorgio Agamben, who write books in / of the pandemic. Inspired by these thinkers, an author raises her impressions about a pandemic and its reflexes in an early childhood education institution, none of which was the same during the period of social detachment.
\end{abstract}

Keywords: Pandemic; Child education; Quarantine journal.

Somos piores que a COVID-19.

Ailton Krenak (2020)

Desejo iniciar essa escrita, parafraseando Krenak, pois assim como ele, adiei compromissos e parei de andar pelo mundo. O meu mundo, antes da pandemia era trabalhar em duas matrículas, como muitas professoras brasileiras. Esse ritmo de trabalho me distanciava de alguns desejos. Desde que terminei o Doutorado em Educação, em fevereiro de 2019, não conseguia retornar para o grupo de pesquisa. Isso me incomodava. Daí vem a pandemia e o distanciamento social freou meu ritmo de trabalho e me aproximou novamente dos encontros do Grupo de Pesquisa Infância e Saber Docente, que passei cerca de um ano distante das discussões semanais. Com as recomendações de distanciamento, os encontros passaram a ser remoto e vi aí a oportunidade de estar imersa no grupo nesse novo formato. 
No primeiro encontro online, em março de 2020, nossas primeiras reflexões diante da pandemia foram unanimes: Como pesquisar, estudar, ler e escrever em tempos tão desafiadores como esses que estamos vivendo? Essa pergunta me deixou reflexiva, pois gostaria de retomar alguns projetos, na quarentena imposta pela pandemia. Precisava buscar inspiração, enfim, estratégias de sobrevivência, assim como fiz quando passei a fazer atividades físicas, paralelas às atividades de um doutorado sanduíche no exterior. Estratégias para sobreviver!

Uma das primeiras estratégias que pensei para me inspirar foi procurar pesquisar e me aproximar de autores que estavam pensando e escrevendo acerca da pandemia do coronavírus. A primeira produção localizada foi de Boaventura de Sousa Santos e o seu livro "A cruel pedagogia do vírus". Li em uma velocidade alucinante, como se toda a complexidade do texto, precisasse ser destrinchada com urgência. Na primeira oportunidade apenas li e tomei um "soco" de realidade. No dia seguinte, senti a necessidade de fazer uma resenha, reler aquele texto. Essa resenha acaba de ser publicada pela Revista Olhar de Professor, com o título “Aproximações e reflexões diante da "pedagogia do vírus” (LOPES, 2020).

O livro "A cruel pedagogia do vírus" de Boaventura reflete algumas de suas ideias ao longo de sua trajetória acadêmica e pessoal. Ele se pergunta: "Que potenciais conhecimentos decorrem da pandemia do coronavírus?"

O texto é dividido em cinco capítulos. No capítulo 1 "Vírus: tudo o que é sólido se desfaz no ar”, o autor começa afirmando que é possível conhecer a qualidade das instituições sociais em situações de normalidade, mas principalmente em momentos de crise.

A pandemia vai reforçar o que o autor chama de "sociologia das ausências", pois são muitos os que já eram invisíveis, como os refugiados e imigrantes, por exemplo, e que com a atual situação reforçam sua condição de vulnerabilidade extrema. Boaventura acredita que essas realidades duras são tangíveis, talvez seja necessário só abrir nossas janelas para vê-las. No Brasil temos observado esses "ausentes" diariamente nas filas da Caixa Econômica Federal, banco que distribui o auxílio emergencial no valor de R $\$ 600,00$ por mês, durante 5 meses, para a população atingida diretamente pela pandemia.

No capítulo 2 "A trágica transparência do vírus", o autor inicia afirmando que a pandemia demonstra muito claramente, que será, o modo como ela será interpretada e avaliada que vai determinar o futuro do nosso planeta.

Santos chama atenção para o nosso papel, enquanto intelectuais diante da realidade pandêmica. Para ele, devemos escrever com o mundo e não apenas sobre o mundo, pois parece ser fácil ter pensamento extraordinário em tempos comuns, mas o autor nos desafia a Revista Interinstitucional Artes de Educar. Rio de Janeiro, V. 6 - N. Especial II - p. $490-502$ (jun - out 2020 )491 "Educação e Democracia em Tempos de Pandemia". DOI: 10.12957/riae.2020.52249 
pensar de forma inédita em tempos tão desafiadores. O que Boaventura chama de "claridade da pandemia" acaba por criar um véu que nos impede de ler e dialogar com esse mundo tão caótico. Como quando saímos de uma caverna e nos deparamos com o Sol. Assim também a democracia corre risco nesses tempos, já que o Estado, sob o pretexto de resguardar vidas, acaba tomando medidas extremas de vigilância e controle.

Para Boaventura a pandemia tem demonstrado que o tempo dos intelectuais de vanguarda findou. Esses intelectuais precisam estar mais conectados com as necessidades do mundo. A edição dessa revista parece ser uma aproximação disso, quando suspendem-se outras discussões para pensar no que tem mobilizado o mundo e que traz repercussão para a educação. Esse abismo entre sociedade e o pedestal onde se encontram alguns intelectuais, acaba por aproximar a população de outros interlocutores que se aproximam de seus anseios, entre eles: lideranças de religiões conservadoras e radicais.

O capítulo 3 "A sul da quarentena" é o ponto central das reflexões de Boaventura, já que nele o autor faz referência do que ele chama de "epistemologias do sul". Para ele "uma epistemologia do Sul assenta em três orientações: aprender que existe o Sul, aprender a ir para o Sul, aprender a partir do Sul e com o Sul" (SANTOS, 1995, p. 508).

Devemos estar atentos para o caráter discriminatório da quarentena, já que existe um consenso do quanto ela é difícil para todos, mas especialmente mortal para grupos minoritários e mais vulneráveis. Essas pessoas são o que o autor chama de "Sul”, que como já vimos, não é uma localização geográfica, mas sim um espaço-tempo social, político e cultural. Entre eles estão: os autônomos, os trabalhadores e as populações de rua, os moradores das periferias pobres (favelas), os refugiados, os deficientes e os idosos.

E as crianças brasileiras? Sem escola, ficam também sem alimentação? E os deficientes convivendo diariamente com o capacitismo, ou seja, tem sua mobilidade urbana limitada, o que os impõe a uma permanente quarentena!

No capítulo 4 "A intensa pedagogia do vírus: as primeiras lições”, Boaventura levanta alguns aprendizados iniciais que podemos ter diante de suas primeiras impressões em plena pandemia. Estas lições dão o gancho para o último capítulo "O futuro pode começar hoje" que é um sopro de esperança, onde podemos nos mobilizar para um futuro que comece agora na pandemia. Mas esse retorno ao "normal" será desafiante para todos, crianças e adultos, que vão sentir o impacto de todo esse tempo em suspenso. Muitas serão as perguntas, temos um futuro ainda mais incerto. Pois para Boaventura, já estamos acerca de quatro décadas vivendo uma quarentena que é política, ideológica e cultural. 
A leitura de Boaventura acabou me despertando o desejo de ler outros autores que conseguem, como ele sinalizou, pensar de forma extraordinária, em tempos igualmente extraordinários, raros e inéditos. Foi então que tive acesso ao livro "Reflexões sobre a peste", de Giorgio Agamben, que é um dos principais pensadores da contemporaneidade. O texto é um diário crítico da quarentena escrito na Itália, com textos divulgados em uma coluna do autor, denominada "Una voce" no site da Editora Quadlibet, entre os dias 26 de fevereiro até 13 de abril de 2020. Desse modo, o livro acaba representando um recorte necessário para sua publicação.

Senti necessidade de também escrever uma resenha do livro de Agamben, pois notei que existia um entrecruzamento nas ideias desses autores que ousam escrever o que pensam na e da pandemia.

O livro é dividido em 6 artigos, o primeiro "A invenção de uma epidemia", foi escrito em 26 de fevereiro de 2020. Nele Agamben observa que na contemporaneidade existe uma tendência em usar o estado de exceção como uma conjuntura normal de governo. Desse modo, o estado de pânico coletivo gera o pretexto ideal para limitar a liberdade da sociedade. Devemos estar atentos a esta prática perversa, pois em nome de nossa necessidade de segurança, satisfazemos aos desejos dos governos.

O segundo artigo "Contágio", foi publicado no dia 11 de março de 2020, mesmo dia em que a Organização Mundial da Saúde (OMS) mudou a classificação do coronavírus de epidemia para pandemia. Nele Agamben chama atenção para o fenômeno que ocorreu com o fechamento de escolas e universidades. Do dia pra noite as atividades online se alastraram numa velocidade tão rápida quanto o vírus. Substituindo assim as conversas políticas e culturais, por simples mensagens digitais. Em nome de uma aparente segurança, teremos máquinas substituindo pessoas, para se evitar ao máximo qualquer contágio. Deveremos estar atentos para garantir direitos que foram duramente conquistados. Urge denunciar, que muitos estudantes brasileiros não tem acesso a educação online definida por muitas redes de ensino. Isso significa dizer que crianças e jovens estão sem estudar nesse período de distanciamento social e, em muitos casos, longe do único lugar que lhes dá acesso à alimentação e segurança: a escola.

O terceiro artigo "Esclarecimentos" foi divulgado em 17 de março de 2020, dia em que as fronteiras de diversos países no mundo começaram a ser fechadas. Nele o autor alerta que o medo é um péssimo conselheiro, mas que também faz emergir coisas que não percebíamos, o que o autor vai chamar de "a vida nua". O pavor por perder a vida, acaba por segregar as pessoas, ao invés de uni-lás. 
O quarto artigo "Reflexões sobre a peste", veio a público em 27 de março de 2020, mesmo dia em que a OMS convocou líderes do G-20 $0^{\mathrm{ii}}$. Nessa publicação Agamben, chama atenção para o mesmo que Boaventura e também Krenak (como veremos mais adiante) estão sinalizando, que nossos modos de vida precisam ser revistos e de que não é possível viver como antes.

O quinto artigo "Distanciamento social" foi divulgado no dia 6 de abril de 2020, quando no mundo já contabilizava quase $90 \%$ dos estudantes do planeta sem aulas, cerca de 1,5 bilhão de crianças e jovens. Para Agamben uma comunidade fundada no "distanciamento social", não pode ser politicamente visível e nem humana.

No último artigo desta coletânea, temos "Uma pergunta", que foi publicado no dia 13 de abril, quando no mundo temos a trágica marca de 100 mil mortos. O limiar que separa a humanidade da barbárie já foi ultrapassado diante da pandemia. Agamben lança a seguinte pergunta: "Como pôde acontecer que um país inteiro tenha sem perceber, desmoronado ética e politicamente diante de uma doença?" No contexto brasileiro essa pergunta ecoa de forma intensa, já que estamos diante da total negligência política.

Para confrontar as marcas desses tempos que estamos vivendo, Agamben busca Tucídides (460-400 a. C.) quando relata a História da Guerra do Peloponeso: “A peste marcou para a cidade o início da corrupção". E continua: "Ninguém mais estava disposto a perseverar naquilo que antes julgava ser o bem, porque acreditava que pudesse talvez morrer antes de alcançá-lo". Nada mais atual para os dias de hoje.

Essas leituras passaram a deslocar o meu olhar para o meu isolamento no cotidiano. Estava trancada em um apartamento sem varanda na Zona Norte do Rio de Janeiro. Eu já residia no imóvel há pouco mais de um ano, mas só com a pandemia foi possível perceber que não havia luz solar no seu interior em nenhuma hora do dia. Daí lembrei, que alguns anos antes, numa formação do Proinfantiliii, em 2010, centenas de formadores, incluindo eu, passamos uma semana confinadas em um confortável hotel no Centro do Rio de Janeiro. Enquanto todas as pessoas avaliavam o evento, a Professora Léa Tiriba ${ }^{\text {iv }}$ nos alertou da falta que o Sol fez naquele encontro. Inevitável lembrar esse episódio, pois o confinamento nos priva de elementos que nos passam despercebidos: o sol, a brisa, a água do mar, a chuva.

Pensar na falta que o Sol me fazia, me aproximou de ler "O amanhã não está à venda", de Ailton Krenak, com quem iniciei esse itinerário que compartilho com vocês. Assim como os outros autores que li, mais uma vez rascunhei uma resenha. Acredito que essa necessidade veio do meu desejo de também elaborar na minha cabeça, as minhas próprias impressões sobre este período tão desafiador. 
Ailton Krenak é uma das maiores lideranças indígenas na contemporaneidade. Sua atuação como ativista de movimentos socioambiental e de defesa dos direitos indígenas, resultou na conquista de um capítulo referente às questões dos índios na Constituição Brasileira de 1988. Na lei essa conquista foi importante, mas a luta é constante, pois esses grupos sofrem inúmeros ataques, que se agravaram com a pandemia.

O livro de Krenak se inspira em algumas referências, vozes que ecoam junto com o autor, entre elas Foucault, Carlos Drummond de Andrade, Domenico De Masi e Albert Camus. $\mathrm{O}$ autor apresenta um posicionamento bem crítico, às atitudes do atual presidente diante da pandemia do coronavírus. Para Krenak, o discurso político evidencia uma profunda banalização da vida, de modo muito cruel, como verificamos no contexto brasileiro. Afirmar, por exemplo, que a economia é o mais importante, seria o mesmo como acreditar no navio sendo mais importante que a própria tripulação.

Krenak inicia suas reflexões falando do lugar geográfico que ele ocupa, a aldeia Krenak, no médio Rio Doce. Assim como todos nós, ele fala o quanto à pandemia nos paralisou, mas ao mesmo tempo ele alerta que muitos grupos já viviam esse confinamento involuntário há muito tempo. Os próprios índios já viviam encurralados e refugiados em seus territórios, já que Krenak fala da sua própria experiência. Tal nuance nos remete as reflexões já apontadas por Boaventura, quando aborda essa quarentena involuntária que os moradores das favelas, as populações de rua, os refugiados, os deficientes, já viviam. Ao mesmo tempo esse confinamento nos faz mais resilientes e resistentes. Mas até quando resistiremos?

Krenak observa que diferentes grupos podem vivenciar de formas distintas o distanciamento social, através de suas vivências e experiências de vida. Enquanto eu estou trancada num apartamento, com o confinamento imposto pela pandemia; ele planta milho e árvore no seu isolamento integrado com a natureza.

A pandemia nos mostrou de forma contundente, que o mundo pode parar sim, ao contrário do que poderíamos pensar. O funcionamento do mundo entrou em crise. Estamos todos experienciando o que os grupos perseguidos já vivenciavam há muitos anos. Antes, os índios estavam ameaçados de extinção, com a pandemia estamos todos, enquanto sociedade mundial. Nossa humanidade é mais mortal que a COVID-19. Para Krenak a humanidade é uma mentira, nos divorciamos dela. Somos de fato uma humanidade?

Estamos cavando um enorme fosso de desigualdades entre os povos, sendo assim, não estamos todos "no mesmo barco", como se pode pensar. Uns poderão comprar as melhores máscaras faciais para se proteger do contágio, outros vão improvisar usando couve ou sacola plástica no rosto. As grandes filas que se formaram na Caixa Econômica Federal, durante a Revista Interinstitucional Artes de Educar. Rio de Janeiro, V. 6 - N. Especial II - p. 490-502 (jun - out 2020)495 "Educação e Democracia em Tempos de Pandemia”. DOI: 10.12957/riae.2020.52249 
pandemia, para tentar receber o auxílio emergencial, demonstram um desespero coletivo: ou se morre do vírus, ou se morre de fome? Existe escolha para esses invisíveis? Para Krenak o que acompanhamos é uma naturalização de uma sub-humanidade, que já viviam na miséria e hoje enfrentam o aprofundamento dessa barbárie.

Krenak reforça o reequilíbrio da natureza diante do confinamento das sociedades, já que a ecologia segue se reestruturando. Vale lembrar que o coronavírus mata apenas seres humano, e somos apenas $0,01 \%$ da vida planetária, como já nos alertou Boaventura em suas reflexões sobre a "pedagogia do vírus". Krenak afirma que não faríamos falta na biodeversidade, pelo contrário. A mãe Terra parece querer ensinar e dizer: "Filho, silêncio".

No que diz respeito à infância, Krenak acredita que o tempo da quarentena pode representar uma viragem em nossa relação com as crianças, pois assim como nós, elas também estão sentindo medo e podemos afastar sentimentos ruins lhes contando histórias. Assim espantamos nossas angústias e também as delas. Com atitudes simples, podemos pensar num outro mundo possível. Pois, para superar o coronavírus, teremos primeiro que ter cuidado e depois coragem.

O mundo está em suspensão e não sairemos dessa pandemia do mesmo jeito que entramos nela. Para Krenak: "Tomara que não voltemos à normalidade, pois, se voltamos, é porque não valeu nada a morte de milhares de pessoas no mundo inteiro." Pois depois que esses tempos sombrios forem superados, suas marcas profundas ficarão e não poderemos de um dia para o outro ligar todas as máquinas que foram desligadas e tocar nossas vidas. Teremos muitas cicatrizes da pandemia.

Krenak afirma que já faz algum tempo que ele não programa atividades para "depois", pois para ele precisamos parar de ser convencidos em afirmar que estaremos vivos no dia seguinte. Com a pandemia, nossa primeira atitude foi cancelar nossas atividades e projetos. Seria isso o suficiente? Não, não basta alterar o calendário. Já que acreditar que simplesmente adiar os compromissos, como se tudo pudesse voltar ao normal é viver do passado. O futuro é agora! Os empresários que saem em seus automóveis importados para protestar podem morrer com o vírus, assim como os funcionários que eles desejam que voltem ao trabalho a qualquer custo, como se fossem escravos contemporâneos. Krenak alerta que a Covid mata quem está dentro ou do lado de fora de uma Land Rover. "Temos de parar de vender o amanhã." Mas, as estatísticas tem demonstrado que o vírus é muito mais mortal na população pobre e periférica.

Estar atenta ao outro, que fala de um lugar tão diferente do meu é respeitar conhecimentos e sabedorias que revelam uma ancestralidade que esteve tanto tempo à margem. Krenak me ajudou a rascunhar minhas próprias proposições. Algumas chamadas 
para publicações acadêmicas começaram a demandar a temática. Comecei a pensar da seguinte forma: quem sabe, minhas inspirações poderiam gerar novas ideias. Mas pensei que escrever nesse período, não poderia ser simplesmente redigir um artigo nos "moldes" acadêmicos. Seria preciso desafiar a lógica acadêmica, que nos impõe suas "normas", mesmo quando nosso principal objetivo diário é sobreviver. Daí começou a "martelar" na minha cabeça, nas longas noites de insônia que a pandemia descortinou na minha rotina, a ideia de um diário da quarentena.

Acredito que esse desejo de diário veio da minha adolescência, quando eu escrevia ali minhas angústias, na tentativa de pensar uma rota de saída, ou simplesmente documentar tempos inéditos. Por que no diário resiste essa subversão, eu só escrevo aquilo que quero lembrar para a posteridade. Eu, por exemplo, não gostaria, mas preciso lembrar que escrevo no olho do furacão, no meio de uma pandemia, que até o dia de hoje (30 de junho de 2020), já matou 505.518 pessoas no mundo, segundo dados oficiais. Em nosso país a negligência política e social já matou 58.385 vidas: adultos, crianças, idosos e jovens. São vidas “inumeráveis". Esse é o nome dado no Brasil a um grupo que tem dedicado seu tempo e seus esforços para fazer um memorial virtual dedicado à história de cada uma das vítimas do coronavírus (www.inumeraveis.com.br). E a população assiste incrédula o representante máximo do atual governo respondendo quando o número de mortes no Brasil ultrapassou a China: "Lamento! Quer que eu faça o quê? Eu sou Messias, mas não faço milagre!"

Assim como o diário, na quarentena retomei outro passatempo da adolescência, o bordado de ponto e cruz. Acredito que não podemos nos cobrar muito nesse período, tenho procurado ser mais flexível comigo. O diário e o bordado materializam esse desejo, em que posso num dia escrever uma resenha e num outro bordar por horas. Tem ainda dias em que posso testar um bolo que fará parte de um caderno de receitas da quarentena, que estou elaborando com meu filho de 14 anos.

A ideia do caderno de receitas foi inspirada numa das primeiras lives que assisti, com Francesco Tonucci, em 25 de abril de 2020, intitulada "Por uma boa escola em tempos de coronavírus“. Esses encontros virtuais tomaram uma proporção inimaginável, entre opções acadêmicas e musicais. São tantas as opções que nos dois casos, passei a ficar mais seletiva. Acredito que com essa era de live, a democratização no compartilhamento dos saberes ficou mais acessível e justa, pois muitas das professoras conseguem participar ou promover os vários eventos, colóquios, lives e seminários online. 
Meu filho fez na quarentena, uma descoberta que eu já tinha feito anos antes quando não consegui levar adiante uma especialização à distância, que não somos do "EAD”, somos da "invencionice", como nos bem lembrou Manoel de Barros.

Voltando ao diário propriamente dito, não poderia deixar de relatar a minha experiência inédita de tomar posse como Professora do Ensino Básico, Técnico e Tecnológico (EBTT) da Educação Infantil do Coluni UFF no meio da pandemia. Talvez o clima de instabilidade política que estamos vivendo, justifique arriscar nossas vidas para chamar concursados.

Foi preciso muita coragem, para fazer todos os exames admissionais, solicitar vacância em outras duas matrículas e apostar numa nova rota. Coragem para atravessar a Ponte Rio-Niterói munida de comprovantes que justificassem "furar" a quarentena. Assim passei a fazer parte, de forma remota de um grupo de educadoras que já há alguns anos militam na Educação Infantil pública, presencialmente e, agora, remotamente. Minha apresentação formal foi numa tela fria de computador. Passei a participar de animadas reuniões de planejamento pedagógico. Nossa preocupação tem sido pensar atitudes que possam de fato atender demandas urgentes, como a fome, com a distribuição de cestas básicas, mas outras ações que consigam dar o tom da Educação Infantil, com interações e brincadeiras. Foi assim que algumas estratégias passaram a nortear nossas práticas remotas. Foi consenso em nosso Colégio Universitário afirmar que não acreditamos numa Educação Infantil à distância.

$\mathrm{Na}$ Educação Infantil do Coluni UFF estamos trabalhando em algumas frentes com cunho pedagógico, reafirmando que só poderá ser possível um retorno, quando for seguro. Acreditando que a escola é um lugar onde guardamos e colecionamos experiências e afetos.

Uma das primeiras ações coletivas do Coluni UFF foi criar um endereço eletrônico que pudesse reunir essa coleção de experiências e afetos. É o "Quarentuni”, o Coluni-UFF na quarentena (https://quarentuniuff.wixsite.com/coluniuff) que reúne todas as iniciativas do colégio, da Educação Infantil até o Ensino Médio. Eis a apresentação que pode ser observada no endereço:

O propósito deste site é promover o contato entre os diferentes membros da comunidade escolar. As publicações aqui inseridas não estão vinculadas à escolarização, não são obrigatórias, não contam como carga horária letiva nem substituem as aulas presenciais. Este espaço virtual foi criado para que possamos nos reaproximar neste período de reclusão e para valorizar tudo aquilo que torna a nossa escola tão especial. Que saudade de tudo que vivemos no Coluni-UFF: as amizades, as aulas, as relações entre crianças, estudantes, professores e demais profissionais da educação! Desejamos que 
nosso carinho e nosso afeto uns com os outros possam nos ajudar a enfrentar a quarentena juntos! Entre e divirta-se!

Na Educação Infantil sentimos necessidade de fazer uma documentação pedagógica virtual através de uma página privada no Instagram chamada "praguardar.eiuff”, que tem representado esse caráter de priorizar as relações, com fotos e vídeos de um passado recente, que estava arquivado e que com o tempo em casa imposto pelo distanciamento, sentimos o desejo de documentar.

Outra ação que prioriza as interações foi denominada de "Balburdinha", um encontro virtual por grupos de crianças através do Google Meet. Essa interação foi possível após a unidade verificar que todas as 57 famílias que compõem a Educação Infantil do Coluni-UFF poderiam acessar a plataforma por celular ou computador e que tinham acesso à internet. Conheci o grupo de professoras, crianças e famílias por uma tela, elas entrando na minha casa e eu entrando nas delas. Foi assim, através do Balburdinha do Grupo Verde, que eu conheci as crianças que estarei convivendo após a quarentena. Foi uma deliciosa balbúrdia, onde todas as crianças falam ao mesmo tempo, desejando mostrar suas novidades, aliviar as saudades que sentem dos amigos e amigas, como numa rodinha presencial.

Já realizei tantas rodinhas como essas, quando fui professora substituta entre os anos de 2007 e 2009, na mesma unidade, que na época se chamava Creche UFF. Então minha posse em 2020 é um retorno à casa, como contei no boletim com publicação virtual da Educação Infantil do Coluni-UFF, denominada "Escorrega":

O ano era 2007 e eu ganhei um belo presente: ser aprovada no primeiro concurso simplificado para professora substituta da Creche UFF, nome que nossa Educação Infantil do Coluni/UFF era conhecida na época. Foi na semana do meu aniversário, em junho de 2007, que conheci adultos e crianças e que comecei a viver uma trajetória muito feliz nesse lugar. Era uma volta pra casa, depois de fazer faculdade de Pedagogia na UFF. Vivi dois anos muito bacanas, de aprendizagens, brincadeiras e alegrias. Lembro que na época descobrimos muitas coisas incríveis num projeto chamado "Aranhas" e foram as crianças que inventaram a ideia de "fazer" teias com cola de isopor nas mãos... Quantas lembranças! Mas um dos projetos mais legais que vivenciei com crianças e adultos daqui foi o projeto "Odisséia", que foi um mergulho na cultura grega antiga. Foi das crianças a ideia de construir um grande cavalo de Tróia feito de papelão e que cabíamos quase todos nós dentro dele, igualzinho na história de Homero. Foi um verdadeiro "presente de grego!" No final fizemos uma grande festa grega! Mas, em 2009 tive que me despedir dessa "minha casa". Andei por muitos lugares, mas por uma grata alegria, ganhei novamente de presente a oportunidade de trabalhar aqui, na Educação Infantil do Coluni/UFF. Fiz concurso para Professora do Ensino Básico Técnico e Tecnológico, na área de Educação Infantil. Tomar posse no dia 7 de abril de 2020, no meio de uma pandemia, foi um desafio, mas agora já participo à distância dos trabalhos que a equipe 
vêm desenvolvendo e conto os dias para conhecer todos vocês, crianças e adultos, para fazer muita coisa boa juntos. Feliz em voltar pra casa... Até lá! (BOLETIM ESCORREGA UFF, 2020).

Todas essas vivências pandêmicas me fazem refletir acerca do momento que vivemos e de seus impactos na Educação e mais particularmente na Educação Infantil. "Sabemos" ser professoras em tempos normais, nos formamos para isso. Mas não sabemos ser professoras na pandemia e num futuro retorno. Vamos precisar nos forjar. Intuímos o que não queremos ser. Olhar as imagens que vêm de retornos da rotina escolar é no mínimo angustiante e preocupante. Sei o que não quero! Não quero crianças em quadrados riscados no chão, a não ser que seja para brincar de amarelinha. Não quero brinquedos interditados num canto da sala, nem dias alternados para cada grupo frequentar a escola, nem a abertura apenas para aqueles que seus pais e mães trabalham. Por que aí não é educação e sim assistência. E não estou aqui negando a sua atuação. Acredito que precisamos dialogar e atuar nesses tempos extraordinários com muitas outras áreas: Assistência Social, Enfermagem, Medicina, Arquitetura, Psicologia, etc.

Como a Educação Infantil que acredito - das interações e brincadeiras, dos interesses das crianças como mobilizador da prática - pode sobreviver naquelas circunstâncias das imagens que nos são endereçadas mundo afora? Como produzir algum tipo de protocolo, quando na escola pública onde meu filho cursa o último ano do Ensino Fundamental, são 42 jovens em uma sala? A pandemia traz a insegurança na nossa própria formação, pois já é um desafio ser professora de Educação Infantil que pensa "fora da caixa", que acredita numa concepção que já respeita em tempos comuns os corpos, os afetos, as interações, enfim, as crianças e suas singularidades. Mas eu não sei ser professora de Educação Infantil na pandemia, reafirmo.

As ações que estão me forjando nessa pandemia, enquanto professora da primeira infância, estão me resignificando, me atribuindo um novo olhar. Senti a necessidade de fazer uma lista de todas as invencionices da quarentena, uma espécie de currículo Lattes pandemônico, onde pude conferir itens heterogêneos, onde foi possível subverter outras lógicas. A minha favorita foi revisitar fotos antigas e "escrever" um artigo fotográfico através de imagens. Não estou preocupada (e nunca estive!) se a revista tem classificação alta ou não, mas se a proposta me desperta o desejo de publicizar minhas ideias no meio de uma pandemia (como faço agora!) eis um grande ato de coragem.

A educação é direito das crianças! E não podemos esquecer disso, em nenhum protocolo, que parecem querer nos obrigar a pensar agora. São protocolos para um pós- 
pandemia! E assim retorno a Krenak (2020): "Há muito tempo não programo atividades para depois. Temos que parar de ser convencidos. Não sabemos se estaremos vivos amanhã. Temos de parar de vender o amanhã."

Portanto, para elaborar a minha própria voz diante da pandemia, eu precisei ouvir as vozes de quem já vivia uma pandemia que era anterior a este vírus, a pandemia do descaso, como ficou tão latente nas leituras de Boaventura e Krenak. Uma invisibilidade que atingem adultos e crianças. As crianças têm direito à vida e nós também, pois precisamos pensar que por mais que elas tenham sua própria voz e seu modo de pensar, vivemos num mundo em que ainda precisamos ser interlocutores dessa infância. Precisamos lutar coletivamente por um retorno ao cotidiano escolar, que só seja possível quando pudermos preservar todas as vidas. Enquanto esse retorno não acontece, precisamos garantir a manutenção de direitos, conquistados tão duramente e não transformar a educação num "EAD".

Enquanto o tão esperado dia de nos abraçar e nos tocar não chega, até lá, podemos nos encontrar numa chamada de vídeo e todo mundo falar junto (famílias, professoras, crianças e gestão) e fazer uma grande "balburdinha", que é o que de fato faremos, dessa vez presencialmente, quando tudo isso acabar.

Vivemos hoje a quarentena dentro de outra quarentena. Talvez tenhamos que superar primeiro a pandemia provocada pela negligência política, para depois vencer a pandemia do vírus. Muitas serão as mudanças pós-quarentena, que demandará de nós uma viragem cultural, ideológica e epistemológica que garanta a continuidade de uma vida mais digna para os seres humanos. Dia 110 da quarentena.

\section{Referências}

AGAMBEN, Giorgio. Reflexões sobre a peste. Quodlibet, 2020.

BARROS, M. Memórias inventadas - a Terceira Infância. Rio de Janeiro: Planeta do Brasil, 2008.

KRENAK, A. O amanhã não está à venda. Companhia das letras, 2020.

ESCORREGA. Boletim Informativo da Educação Infantil da Educação Infantil do Coluni $U F F$. Edição Especial. Ano 2, n. 7, maio 2020.

LOPES, I. P. Aproximações e reflexões diante da "pedagogia do vírus". Revista Olhar de Professor, v. 23, p. 1-4, 17 jun. 2020. Disponível em:

$<$ http://www.uepg.br/olhardeprofessor>. 
SANTOS, Boaventura de Sousa. Pela mão de Alice. O Social e o Político na PósModernidade. São Paulo: Cortez, 1995.

. A cruel pedagogia do vírus. Edições Almedina, 2020.

WEBINAR SEMINÁRIO ONLINE “Por una buena escuela en tiempo de Coronavirus", Integratek. Webinar apresentado por Francesco Tonucci. Espanha, 25 de abril de 2020.

\footnotetext{
i Doutora em Educação pela UERJ; Professora EBTT da Educação Infantil do Coluni UFF; E-mail: isabelauff@bol.com.br Rio de Janeiro. Brasil. ORCID: https://orcid.org/0000-0002-3785-593X

ii O G20 (Grupo dos 20) é um grupo constituído por ministros da economia e presidentes de bancos centrais dos 19 países de economias mais desenvolvidas do mundo, mais a União Europeia.

iii Curso a distância de formação para o magistério, em nível médio, oferecido para professoras(es) em exercício nos sistemas de ensino e que não possuíam a formação mínima exigida pela Lei de Diretrizes e Bases da Educação Nacional (LDBEN), Lei 9.391 de 1996.

iv Educadora-ambientalista, Professora da Universidade Federal do Estado do Rio de Janeiro (UNIRIO). Coordenadora do Grupo de Pesquisa "Infâncias, Tradições Ancestrais e Cultura Ambiental (GiTaKa) e do Núcleo Infâncias, Natureza e Artes (NiNA). Membro do Movimento Articulação Infância, do Fórum Permanente de Educação Infantil do Rio de Janeiro e do Movimento Interfóruns de Educação Infantil do Brasil (MIEIB).

v Sigla utilizada para denominar a Educação a Distância.
} 